\title{
REALIZATION OF AGRICULTURAL AND FOOD PRODUCTS ON CONSUMER MARKETS
}

\author{
I. Nencheva-Ivanova* \\ Trakia University, Stara Zagora, Bulgaria
}

\begin{abstract}
In order to meet the needs of consumers, products need to be delivered wherever they are needed. This is the main goal of each manufacturer through its distribution policy.

From the point of view of their purpose, agricultural products can also be regarded as products for direct consumption and as production resources for processing plants. The specificity of individual agricultural products defines the main channels of realization.

The choice of delivery option depends on the nature of the product, the financial situation of the manufacturer, the intermediary or the processor, the market characteristics, the traditional channels of realization, the channels used by the competitors, etc.
\end{abstract}

Key words: market, trade, agricultural policy, distribution

After Bulgaria's accession to the European Union, the national market has become part of the internal market of the Community and Bulgarian producers and traders face a number of challenges related to the size and structure of exports of agricultural products. Under the conditions of fierce competition, the products produced in accordance with the European requirements for good agricultural practice and food safety have a successful realization on the international markets. Because of the more favourable economic conditions for trading in the European single market, trade flows are gradually being redirected to EU countries at the expense of other economic communities and regions.

The major challenge facing the Bulgarian agricultural sector after 2007 is the reconciliation of the Common Agricultural Policy (CAP) with the national agricultural policy, which is proving to be a decisive factor for the development of the Bulgarian agriculture. Although in recent years the positive effect of the development of the

\footnotetext{
*Correspondence to: Assos. prof. Iskra Nencheva - Ivanova, PhD; Trakia University, Faculty of Economics, Stara Zagora, Bulgaria; e-mail: iskranencheva@abv.bg;www.uni-sz.bg
}

industry is the result of the infusion of European funds and increased growth of national co-payments, agricultural production is still characterized by low competitiveness and insufficient market orientation. All this is due to the problems accumulated over the years. The collapse of the planned economy and the accompanying crisis had a particularly strong impact on agriculture. (Bencheva, $N$. 2012), (Khadzhieva, V., 2007).

Development and adaptation of the agrarian sector to the CAP is linked to various problems by their nature and scale. Despite difficulties, the sector is gradually adapting to the requirements of the CAP (Bencheva, N. 2012). The aim is to make the agricultural sector highly efficient and competitive under the conditions of our EU membership. (Turlakova, T. 2010).

The fact is that agriculture does not have the potential of the industry or IT sector to create added value, but in the context of strong subsidization and increasing demand for food, it is expected to show better results. According to the Agrarian Report, the sector's efficiency continues to decline, labour productivity is well below the national average and incomes are also low. At the same time, the sector provides vital incomes for rural areas. Reasons 
for the current state of the agricultural sector are of diverse nature. Today, there are still small scattered areas, a huge share of small farms, inefficient absorption of subsidies, insufficient investment - both internal and external.

Expectations for the current programming period 2014-2020 where the main goals are to create more employment and accessibility to funding, are well founded. Small producers are given priority assistance and the introduction of an integrated approach is expected to lead to greater efficiency of the sector and the creation of a higher gross national product from agriculture. (Nikolova M., 2013).

With the integration of Bulgaria and the Bulgarian economy into the EU, the competitiveness of agricultural production is becoming one of the most important issue. A problem arises for the future development of agriculture in the emergence of production and marketing in a highly changed macroeconomic environment. Bulgarian producers face new realities and serious challenges. Increasing costs and prices at which agricultural products are offered are adversely affecting export competitiveness.

There are disturbing symptoms of unstable competitiveness in the Bulgarian agricultural sector, the most important of which are:

- reduced agricultural production, which is unable to meet consumer demand, both domestically and internationally;

- prevailing export situation - a high relative share of unprocessed products exported;

- falling of the major part of the agricultural export in the low price levels, which means low competitiveness in terms of quality of export goods, etc.

\section{Impact of Bulgaria's full EU membership on the agricultural sector}

- There are no significant changes in terms of production volume and product structure.

- Accession to the EU was accompanied by unfinished reforms in the Bulgarian agriculture and food sector, and a large number of unresolved issues.

- Accession to the EU and the implementation of the CAP contributes to the competitiveness of the extensive sectors benefiting from support through direct payments.
NENCHEVA-IVANOVA I.

- Problems in horticulture and vegetable production are exacerbated by structural weaknesses in specialized farms.

- The full opening of the internal market for EU goods is positive for consumers and it has increased competition and improved consumer access to quality food products. Free access for food importers, implementation of food safety and quality standards along with the increased diversity of food products have been appreciated by consumers.

- The positive effect of the quality of products offered and their security can be greatly emphasized. Much of the suspected imports from third countries have been stopped. The product range is also expanding.

- Modernization of the sector is a positive process, facilitated by improved access to EU financial resources and enhanced export opportunities in the European market.

- The effect of the price increases that followed the accession could be considered negative because of the ongoing process of gradual alignment of domestic and European price levels. The changes are linked to more competition in the market, especially for products with a high share of value added.

Bulgarian agricultural production after 2000 is relatively stable, but at a level that does not meet its natural potential. The modernization of the sector is far from complete, while there are signs of unbalanced development.

For many years agriculture has been at the heart of Bulgaria's economy. Today, its share in the GDP and in employment is steadily declining. At the same time, agriculture retains its importance and role as a supplier of vital products. The new challenges facing agriculture, as well as the rapid changes in social life, also require the development of agricultural policy as an activity aimed at achieving social goals.

Import and export of agricultural commodities are mainly targeted at EU countries, with the overall trade balance being positive. Since our accession to the EU in 2007, agricultural policy has focused on absorbing agricultural support - through direct payments and the Rural Development Program (RDP).

Bulgaria should strive to achieve its national priorities in agriculture, which means that the country must be actively involved in the process of developing the EU CAP as an 
opportunity to take into account the interests of Bulgarian farmers in building the regulatory framework for European agriculture.

Under these circumstances, the purpose of Bulgaria's agricultural policy is to create conditions for the utilization of the natural agricultural potential of the country, as well as to contribute to the preservation of vital local communities in the country's rural areas.

The successful integration and development of Bulgarian agriculture will very much depend on knowledge of the nature and characteristics of European agriculture. The development of European agriculture is viewed inseparably in relation to rural development, enhancing the comparative advantages and competitiveness of the industries and products produced by them, and highlighting the strengths and weaknesses of production and trade with them. Strengths enable us to realize the opportunities revealed by European integration, and highlight of the weaknesses - to identify adequate changes in economic and agricultural policies, leading to increasing the competitiveness and efficiency of Bulgarian farmers. (ANALYSIS Development of Bulgarian agriculture and...)

The overall outlook for the European agricultural markets and incomes in the coming years is favourable. Factors such as the macroeconomic environment (including the dollar / euro exchange rate and crude oil prices), renewable energy policies, path of technological change, future climate changes, etc. will also greatly affect the future development of agriculture and agricultural markets in the EU.

The way subsidies are distributed (direct payments and national co-payments) does not sufficiently stimulate the production of products for which Bulgaria has very favourable, specific conditions - products with national identity, high taste quality products from other EU countries and these from outside with agrarian export traditions.

The significant increase in the volume of foreign trade in agricultural commodities is a testament to the process of integrating the sector into the world economy and above all into the European economy.

Agriculture is an important determinant of crucial significance for the economic and
NENCHEVA-IVANOVA I.

social development of rural areas, where a considerable proportion of the country's population lives. From this point of view, it is especially important for Bulgaria to use its agricultural potential as a basis for increasing both the welfare of producers and the development of rural areas.

Following EU membership, the relative share of agricultural exports in total exports exceeds their share of imports. This has a positive impact on the development of the agricultural sector and contributes to improving the competitiveness of agricultural production and the efficient use of production resources in agriculture.

Structurally, export of cereals, followed by oilseeds and fruits, have contributed most to the positive trade balance in international trade in agricultural commodities.

The agricultural sector in Bulgaria accounted for $5.5 \%$ of gross value added (GVA), $18.4 \%$ of total country exports and $9.5 \%$ of total imports in 2013, providing employment for over 568,600 people.

The EU remains a major partner in Bulgaria's agricultural trade. Based on this trade union, the country's total trade turnover for 2017 is $70.7 \%$, with agrarian trade amounting to EUR 4,560 million. This is $2.6 \%$ above the level of the previous year. This is due to the $6.9 \%$ increase in deliveries from the EU member states.

According to data of the National Statistical Institute and the Ministry of Health and Food the relative share of the agrarian sector in the total export, import and trade in the country increased to $18.4 \%, 9.5 \%$ and 13.6 respectively in 2013 compared to 2012. In 2017 and 2018 a slight deviation is observed on an annual basis to $16.1 \%$, while an increase in trade and imports is between 12 and $13 \%$.

In 2012 exports of agricultural commodities shrunk by $7.7 \%$ yoy, while imports by $3.8 \%$. As a result, the trade balance in the agricultural trade of the country decreased by $16 \%$ compared to 2011, but remained significantly above the levels of the previous years, exceeding \$ 1.2 milliard. The rates at which agricultural export is increasing are many times higher than the rates at which import is increasing. The foreign trade balance in 
agricultural products is positive and is steadily increasing.

The level and dynamics of trade in agricultural products of Bulgaria in 2017 and 2018 increased compared to the previous periods, due to an increase of export and import of agricultural products by $1.4 \%$ (EUR 3,747 million) and $9.6 \%$ (EUR 2,705 million).

In the trade in agricultural commodities Bulgaria is a partner mainly with the countries of the European Union on the basis of the more favourable economic conditions. In 2017, agricultural trade with the EU increased by $2.6 \%$ compared to the previous year, with the Union share of the country's total agricultural export being $64.5 \%$ and that of agricultural import $-79.2 \%$.

Bulgarian export recorded a slight decrease of $1.0 \%$ in 2017 , as a result of which the positive trade balance in the agricultural trade with the EU contracted by $37.2 \%$ yoy (EUR 274 million). The first half of 2018 saw an increase of $8.8 \%$ compared to the same period of the previous year, or EUR 327.8 million (Agrarian Report).

Bulgarian agriculture and the market orientation of its products have the potential to develop in the future, but this development must be in compliance with the requirements of the European legislation - aimed at improving the quality of the agrarian products offered on the market, as well as continuing the financial support for the respective agricultural sectors. (Kostadinova, 2014).

In recent years, a major priority of Bulgaria's agricultural policy has been to create conditions for more efficient use of production resources in agriculture and increase the competitiveness of agricultural production on international markets. Agriculture is a significant sector of the Bulgarian economy and makes a significant contribution to the formation of the country's foreign exchange earnings.

One of the priority issues of EU agricultural policy is the sustainable functioning of the food chain in individual sub-sectors and sectors of agriculture. In Bulgaria the functioning of the food chain in the context of European integration and globalization is determined by the ongoing processes of modernization and concentration in the various sectors, the challenges in the sphere of production, consumption, trade and the opportunities provided for access to the single European market. (Popov R. et al., 2016).

After Bulgaria's accession to the European Union, Bulgarian agriculture has adapted to the new conditions and requirements on the European market.

Bulgaria's accession to the $\mathrm{EU}$ has led to a change in the structure of trade in agricultural commodities. Due to the more favourable economic conditions for trading in the Single European Market, trade flows are gradually being redirected to EU countries at the expense of other economic communities and regions. Agriculture ranks among the leading sectors of the Bulgarian economy and has made a significant contribution to the formation of the country's foreign exchange earnings.

Traditionally, trade in agricultural commodities has formed a positive foreign trade balance, which after Bulgaria's accession to the EU has shown a trend of steady growth - from about BGN 300 million in 2006 to over BGN 2.3 milliard in 2018.

The prospects for the sustainable development of the Bulgarian food industry are directly related and dependent not only on the opportunities for the development of foreign markets as a result of the liberalization and globalization of trade, but also on maintaining its position on our national market.

It is important for each manufacturer to study the production and diversify the range of products offered. Often products are spatially distant from the place of production. To meet the needs of consumers, products need to be delivered where they are needed. This is the main objective of every producer through its distribution policy.

From the point of view of their destination, agricultural products can be regarded as both direct consumption goods and as production resources for processing enterprises. The specificity of the individual agricultural products determines the main channels for realization. (Nikolova M. et al., 2018).

The choice of delivery option depends on the nature of the product, financial position of the producer, reseller or processor, market characteristics, traditional channels of distribution, channels used by competitors, etc. 
The system of distribution channels is an organized and managed set of different types of units that a company sets up or uses under a contract or on other basis for the purpose of the effective sale of its products.

Distribution channels are individuals or units that are institutionalized in a certain way in terms of organization and management, through which products pass on their way from producer to consumer. Not only do distribution channels meet demand by delivering goods to the right place, at the right quantity, quality and price, but they also stimulate demand with promotional activities (sales promotion, advertising, etc.) of the business entities (i.e. retailers, wholesalers, intermediaries, agents, etc.) that form them.

Each distribution channel starts with the producer and ends with the end users. Like the movement of agricultural products (eg fruits and vegetables) it can be direct, i.e. without passing through intermediate units or indirectly when other units called intermediaries are placed between producer and consumer. (Trendafilov, R., A. Simova, 2000).

The choice of channel is influenced by many factors such as features of the market, product, agents, availability of alternatives, characteristics of the marketing environment. The agribusiness distribution channels do not start from the farmer, in fact it is very difficult to determine exactly where they start from. With the exception of the end user, each participant in the system is both a seller and a buyer, with most sellers having multiple customers.

Proper selection of the most appropriate distribution channel enhances and affirms the image of the company, strengthens consumer confidence in it, offers new horizons for business development. With their marketing channel decisions, managers take a huge responsibility on themselves and on the company. There are two factors that influence the set up and operation of distribution channels:

- controllable - these factors include financial, production, technological, information, raw materials and human capabilities, and nature of produce.

- uncontrollable - these factors include economic and political conditions, competition, business ethics..
NENCHEVA-IVANOVA I.

Interdependence between farmers, processors, distributors and consumers requires coordination.

A producer of fruits, for example, uses a very short supply channel if selling its produce straight from the field. But it can also supply its products directly to the wholesaler, commodity exchange, retail network, or restaurants.

More than $80 \%$ of people working in the agribusiness sector are mainly engaged in trade rather than production. It is known from history that farmers used to take their produce they were not able to consume themselves to the nearby town. They sold it at the price the buyer was willing to pay.

Today, the agricultural market includes many intermediate steps such as buying, collection at a specific location, preservation, packaging, storage, advertising, financing, transport, grading, processing, maintenance, wholesale, retail, risk-taking, insurance, standardization, regulation, inspection and collection of market information.

To reduce losses and also to maintain quality of perishable agricultural products, it is necessary to transfer freshly harvested produce from farmers to final customers as quickly as possible. Although today farmers receive only about a quarter of the money paid by consumers, overall the market is much more efficient than it might otherwise be. Consumers have access to a greater quantity and variety of products at a lower unit price, farmers can sell more produce at a higher unit price, and the agricultural sector can hire more workers as demand for food and textiles and related services require the participation of more people.

The agricultural market system involves interactions both between producers and consumers, and between people, processes and various types of activities carried out between the two end points.

Agricultural channels are the paths that agricultural goods follow from the "door" of farmers up to the "plate" of consumers. There may be multiple intermediaries between the farmer and the consumer, but the length of this path depends on the type of product and the market it seeks. This network of agents, wholesalers and retailers operates relatively 
efficiently to ensure the flow of supplies to consumers.

There are several distribution channels for fruits and vegetables, the first three being of primary importance. (Yordanov, J., V. Boneva, 1995, Kohls R. L., Uhl J. N., 1985, and Padberg D. I., C. Ritson and Albisu, 1997

$>$ Marketplace

$>$ Collection markets

$>$ Retail markets

$>$ Commodity exchanges

$>$ Wholesale markets

$>$ Other

Collection markets are usually organized in the production regions themselves. Their function is to collect small batches supplied by individual producers and turn them into large batches by carrying out certain activities for sorting, grading, packaging and storage, and direct them to different markets.

Retail Markets - Trading of small batches of goods is carried out from producers to retailers. Retailing is the last step on transfer of goods from producers to end consumers. Its intermediary function is carried out by commercial establishments offering products, such as the Metro, Kaufland, Billa and other chain stores.

Wholesale Markets - Trading of large batches of goods is carried out between producers and consumers. Wholesale trade covers a diverse set of all types of buying and selling transactions where the goods subject to exchanged pass through different exchange units until they reach the end consumer. In some cases intermediaries / agents may also be used.

Commodity Exchanges - These are organized centralized wholesale markets. They carry out wholesale of different groups of goods that can be stored for a longer period of time. Commodity exchanges also use intermediaries called brokers who sell on behalf of the producer.

Marketplaces - From the world practice it is known that the marketplace for agrarian products is a meeting place for producers and buyers to sell and buy goods. They are located around larger consumption centers. It is an organized place for wholesale of homogeneous, quality defined, primary, durable, and available products. Companies in these markets have or receive large batches of products from collection markets or from abroad, arrange them into smaller batches and sell them to retailers, hotel and restaurant owners, hospitals, canteens and other institutional buyers.

Organized markets are mainly wholesale markets where trade is carried out by various organizations - farmers, food processing and other processing companies, etc. (Lyubenov L., 2014).

Other forms of trading in agricultural goods are also imposing themselves in the Bulgarian market. These are known as "producer markets". In essence, they are on a temporary (weekly) or permanent basis. For now, these markets are unorganized and without rules. This type of trade must comply with the laws of organized free trade. These markets should be regulated and controlled by the municipal administration, which has the legal rights. These markets can be an intermediate unit in the fruit and vegetable trade.

Although the vast majority of fresh fruits and vegetables are first supplied to the collection markets and marketplaces, yet increasingly most of them are sold directly to consumers at major transport intersections - usually off roads and highways, at market places of producers in cities or straight from the field and garden. This type of trade requires the producer / farmer to take a more active role in sales and perform the functions of the retailer.

Direct sales of agricultural products are constantly expanding nationwide and worldwide because of the following two main reasons:

- Buying of large quantities of cheap and fresh agricultural products (mostly fruits, vegetables, potatoes, etc.) directly from producers avoiding retail stores and local markets due to the widespread use of freezers. This makes the purchase and storage of large quantities of products more profitable.

- Opportunity for consumers to make direct purchases from producers during travel (tourism).

The most common forms of direct sale of agricultural products are:

- Street markets (permanent and weekly) they are organized at a particular place in a certain village, town or city where farmers offer their produce for sale.

- Back door sales - incidental sales of agricultural produce. In this form of direct selling there is no risk of unsold produce, as 
producers do not rely on this method to sell the main portion of their produce.

- Farm shops inside or outside the farm this is a more complex way of direct marketing where producers enter the field of retail trade, which implies compliance with a number of laws and regulations. There are also a number of additional costs for buildings, equipment, personnel costs, keeping of records, and others. There comes the need to maintain a constant range of products (own and outside). In this form of trade the farmer makes profit.

- Through the "gather yourself" system this method of sale is mainly applied to fruits and vegetables. When using this form of trade, the farmer takes a number of risks: the risk of damage to crops and fruit trees caused by the buyers; inability to control direct consumption of produce during picking (loss increase).

This direct sake system requires certain investments (for scales, picking containers, parking lots, service premises, etc.) and compliance with certain standards in the growing of fruits and vegetables.

Municipal markets with developed facilities of indoor and outdoor storage areas, pavilions, tables, etc., where individuals and legal entities trade agricultural products in compliance with the legal regulations of the respective municipality. Municipal markets are the main generators for the development of consumer markets for agricultural and other food products by creating the appropriate environment and conditions for retail business. These markets play a significant social role they support the development of small and medium-sized businesses, support agricultural production, provide a large variety of fresh produce directly from producers, and contribute additional funds to municipal budgets, etc.

- Farmers' markets, exhibitions, fairs and other forms of direct sale channels (so-called short supply chains) of fresh agricultural products organized by municipalities, which provide space and infrastructure. There are no misleading promotions in these markets. Both consumers and sellers have the opportunity to build lasting relationships, striking a balance between supply and demand. The purpose of these short supply chains is to eliminate the intermediary between farmers and end customer, thereby shortening the path of food to the market. In this way, small and mediumsized food producers are stimulated and receive maximum remuneration. Short supply chains are a priority for the European Union as they are the biggest protection for small, medium-sized farmers and all farmers who produce quality food for society from the middleman. Stimulating farmers' markets in the EU and Bulgaria, where clean, fresh and tasty food is offered, is a social way of building mechanisms against rural depopulation (Mendovski, Y. 2018).

- Supermarkets and hypermarkets, discounters (so-called cheap stores), etc. with various coverage (national, regional, local), forming the so-called modern retail. In recent years, modern trade has been on the rise, with a positive impact on the food industry and supply chains.

Competition between marketplaces and supermarket chains that buy directly from producers and engage in wholesale trading is very strong. To increase their competitiveness, companies represented in the marketplaces make changes in their activities:

$>$ They diversify the range of services provided.

$>$ Wholesalers improve their quality of service by offering additional services - prepacking in consumer packaging, repackaging, payment facilities and more.

> Many marketplaces aim to improve their infrastructure and location in order to better meet customer requirements.

$>$ In addition to the aforementioned sales channels, some of the fruits and vegetables are sent directly from farmers to end customers. They have their own warehouses and representative offices in the large consumption centers.

Two factors contribute to the better direct sales from producers to end users - the widespread use of new technologies in the areas of the Internet, trade and rural tourism development. Direct sales of agricultural products and food have centuries-old traditions, but also have great potential, as farmers will be able to sell their produce directly and consumers will be given the right to make informed choices to buy products from certain regions. (L. Lyubenov, 2016).

The general conclusion of this analysis is that the vital structural changes in Bulgarian agriculture have not yet enabled the creation of efficient production that will use the country's agricultural potential.

Agriculture is an important determinant of the economic and social development of rural 
areas, where a significant proportion of the country's population lives.

It is of particular importance for Bulgaria to use its agricultural potential as a basis for increasing both the welfare of producers and the development of rural areas.

\section{REFERENCES}

1. Bencheva, N., 2012, State, Problems and Development of the Agrarian Sector of Bulgaria within the Common Agricultural Policy. Agrarian Sciences, Issue 9, Plovdiv, pp. 7- 17.

2. Turlakova, T. 2010, Problems and Challenges to Bulgarian Agriculture in the First Years after EU Accession. Collection of reports. Varna, p. 26.

3. Hadzhieva, V. 2007, Sustainable development of agriculture in Bulgaria. Economic Alternatives, Issue 5, p. 34.

4. Agrarian Report (2008-2017), Ministry of Agriculture, Food and Forestry, Bulgaria

5. Statistical Reference Book, 2007 to 2018, NSI, S.

6. National Strategy for the Sustainable Development of Agriculture in Bulgaria for the period $2014-2020$.

7. Marina Nikolova, 2013, The State and Challenges of Bulgarian Agriculture after EU Accession, Scientific Papers of the
NENCHEVA-IVANOVA I.

University of Ruse - 2013, Volume 52, Series 5.1

8. ANALYSIS Development of Bulgarian agriculture and the food processing sector within the CAP - economic and social aspects -

9. Yordanov, Y., V. Boneva, 1995, Forms of Trade in Fruits and Vegetables, Journal of Economics and Management of Agriculture, No. 5, page 3

10.Trendafilov, R., A. Simova, 2000, Agromarketing, Bolid Publishing House, Sofia

11.Kohls R. L., Uhl J. N.,1985, Marketing of Agricultural products, Macmillan publishing company, New York

12.Padberg D.I., C. Ritson and Albisu, 1997, Agro-food Marketing, Cab International

13. Nikolova M. et al, 2018, Opportunities and Models for Functioning of Regional Farmers Markets, Research Almanac. Volume 25, Part I., pp. 156-184.

14.Popov R. et al., 2016 Sustainable Functioning of the Food Chain in Bulgaria, Brochure, Institute of Agrarian Economics, S.

15.Lyubenov L. 2016, Bulgarian Consumer Markets for Food and Beverages, Economic Thought, Issue 1, p. 23 